\title{
SISTEMA DE ENTREGA/COLETA DE SENSORES ATRAVÉS DE VEÍCULOS AÉREOS NÃO TRIPULADOS (VANT)
}

\author{
Daniel Augusto de Moura Pereira \\ Universidade Federal de Campina Grande \\ Rua Luiz Grande, S/N - CEP 58540-000 - Sumé - Paraíba - Brasil \\ danielmoura@ufcg.edu.br \\ Alan Marques S Minervino \\ Universidade Federal de Campina Grande \\ Rua Luiz Grande, S/N - CEP 58540-000 - Sumé - Paraíba - Brasil \\ alanmarquessm@gmail.com \\ Romulo Augusto Ventura Silva \\ Universidade Federal de Campina Grande \\ Rua Luiz Grande, S/N - CEP 58540-000 - Sumé - Paraíba - Brasil \\ romuloaugusto@ufcg.edu.br \\ Matheus Yanko da Luz Aires \\ Universidade Federal de Campina Grande \\ Rua Luiz Grande, S/N - CEP 58540-000 - Sumé - Paraíba - Brasil \\ matheusyanko@hotmail.com \\ Danillo Marcus F M do Monte \\ Universidade Federal de Campina Grande \\ Rua Luiz Grande, S/N - CEP 58540-000 - Sumé - Paraíba - Brasil \\ danilodomonte@gmail.com
}

\section{RESUMO}

Esse artigo tem como objetivo mostrar o desenvolvimento um sistema de entrega e coleta de equipamentos e sensores para Veículos Aéreos não Tripulados (VANT). Para tanto, o produto foi desenvolvido a partir de estudos e pesquisas relacionados a área de automação aplicada nos VANT e logística, com o objetivo de transportar sensores de diversos tipos, e com diversas finalidades, para locais de difícil acesso, onde há a necessidade de monitoramento remoto. Utilizou-se de computação gráfica, programação e manufatura aditiva para desenvolvimento do sistema supracitado. $\mathrm{O}$ resultado do projeto do sistema de entrega/coleta de sensores via VANT neste trabalho mostrou viabilidade técnica e econômica do produto desenvolvido, além de possibilitar que pesquisadores, técnicos e pilotos tenham mais flexibilidade, segurança, eficiência e qualidade na coleta de dados a serem coletados a partir dos sensores instalados, bem como inovação nas áreas de Indústria 4.0 e Logística.

Palavra-chave: Indústria 4.0; Logística; VANT; Sensores. 


\begin{abstract}
This paper aims to show the development of a delivery and collection system of equipment and sensors for Unmanned Aerial Vehicles (UAVs). To this end, the product was developed from studies and research related to the area of automation applied in UAVs and logistics, with the purpose of transporting sensors of various types, and for various purposes, to hard to reach places, where there is a need for remote monitoring. We used computer graphics, programming and additive manufacturing to develop the aforementioned system. The result of the design of the sensor delivery/collection system via UAVs in this work showed the technical and economic feasibility of the developed product, as well as allowing researchers, technicians and pilots to have more flexibility, safety, efficiency and quality in collecting data to be collected. from the installed sensors, as well as innovation in the areas of Industry 4.0 and Logistics.
\end{abstract}

Keywords: Industry 4.0; Logistics; UAVs; Sensors.

\title{
Como Citar:
}

PEREIRA, Daniel A M; MINERVINO, Alan M S; SILVA, Romulo A V; AIRES, Matheus Y L; MONTE, Danillo M F M. Sistema de Entrega/Coleta de sensores através de Veículos Aéreos Não Tripulados (VANT). In: SIMPÓSIO DE PESQUISA OPERACIONAL E LOGÍSTICA DA MARINHA, 19., 2019, Rio de Janeiro, RJ. Anais [...]. Rio de Janeiro: Centro de Análises de Sistemas Navais, 2019.

\section{INTRODUÇÃO}

A inovação tecnológica vem sendo um fator decisivo no estilo de vida da sociedade em toda história humana, com a chegada dos veículos aéreos não tripulados, várias atividades foram otimizadas pela rapidez e eficácia, tanto com a facilidade de deslocamento quanto na obtenção e leitura de dados coletados por esses equipamentos. As ações conjuntas dos agentes na busca de novas tecnologias e de novas combinações de uso dessas tecnologias geram conhecimento. A partir do compartilhamento desse conhecimento científico e tecnológico, codificado ou tácito, selecionado pelo paradigma tecnológico vigente, somado ao uso e desenvolvimento de capacidades específicas de aplicação desse conhecimento, é que se chega às novas tecnologias, que podem ser públicas (livre acesso) ou privadas (protegidas por patentes, por lei etc.) (DOSI, 1988).

Com o passar dos anos, os Veículos Aéreos Não Tripulados (VANT) vêm desempenhando um importante papel nas áreas tecnológicas, seja ela na agricultura de precisão, ambiente militar, no setor cinematográfico, entre outras. Sua aplicação nas áreas militares, segurança do trabalho e agricultura vem crescendo substancialmente, geralmente em missões de reconhecimento de terrenos, supervisões em quaisquer tipos de processos produtivos, estudos de imagens de solo, plantações, agropecuária, etc. $\mathrm{O}$ avanço em algumas áreas de tecnologia contribuiu significativamente para o surgimento dessa tecnologia, como: nas áreas de eletrônica, com a potencialização de pequenos sensores; e na área computacional, onde são desenvolvidos os softwares de navegação do VANT, sistema de coleta de dados, captura de imagens em alta resolução, etc. A diversidade e sofisticação envolvidas na criação dos VANT são evidentes, principalmente no âmbito da aeronáutica, 
satélite, navegação inercial, visão computacional, robótica, sensores e fotogrametria (COLOMINA e MOLINA, 2014).

Neste sentido, o uso de VANT representa um avanço das tecnologias de gestão no século XXI pois agrega mais dinamismo na geração de variedades de dados obtidos por sensores embarcados em pequenas aeronaves e estão revolucionando pesquisas e serviços técnicos proporcionando produtos (imagens sintéticas ou multiespectrais) com alta resolução espacial e temporal (LONGHITANO, 2010; CÂNDIDO et al, 2016). Portanto, este artigo tem como objetivo mostrar o desenvolvimento de um sistema de entrega e coleta de sensores em VANT.

\section{REFERENCIAL TEÓRICO}

\subsection{LOGÍSTICA}

A logística tem como finalidade proporcionar o atendimento das demandas com baixo custo e menor prazo para entrega. Ballou (2009) define a logística empresarial como um recurso para atenuar os problemas, observando e identificando todo planejamento, a melhora e a facilidade com que as atividades são realizadas com o objetivo de visar o lucro.

A logística empresarial surge com o propósito de corresponder as necessidades dos clientes, com agilidade no fluxo de entrega de produtos acabados, insumos e serviços.

[...] a logística empresarial estuda como a administração pode prover melhor nível de rentabilidade nos serviços de distribuição aos clientes e consumidores, através de planejamento, organização e controle efetivos para as atividades de movimentação e armazenagem que visam facilitar o fluxo de produtos. (BALLOU, 2009, p.17).

De acordo com Kotler (2006), existem quatro importantes decisões que devem ser tomadas em relação a melhor estratégia logística de mercado:

- Processamento de pedidos;

- Armazenagem dos estoques;

- Estocagem;

- Como os produtos deverão ser transportados.

A agilidade dos fluxos de coleta e entrega de materiais para fabricação de produtos, entrega de um serviço e entrega de produtos acabados faz com que o cliente tenha uma boa percepção do que é oferecido pela empresa. Dito isto, "A logística busca otimizar todos os fluxos de informações e materiais, desde o ponto de origem até o seu ponto final, visando proporcionar níveis de serviços adequados aos seus clientes, com um preço competitivo" (CARVALHO 2004, p.31).

\subsubsection{Logística 4.0}

Com o aumento da globalização em todo mundo, a logística de modo geral vem sofrendo algumas mudanças, entre elas a flexibilização da cadeia de suprimentos, o fluxo de informação mais acessível e ferramentas de controle mais sofisticados.

Para responder essas várias tendências que estão surgindo ao longo do século 21 a cadeia de abastecimento tem aumentado, e por 
consequência, tornado-se mais rápida e com ciclos menores. Dito isto, o diferencial competitivo das atuais e futuras empresas de fornecimento será determinada pela capacidade de flexibilização, planejamento e melhora contínua e reação rápida às mudanças dos meios de produção e consumo (BHARADWAJ et al., 2013; AGARWAL; BREM, 2015; HÄNEL; FELDEN, 2016, p. 261).

O desenvolvimento tecnológico em relação as áreas logísticas vêm estimulando empresas a flexibilizar seus processos, dando assim autonomia a equipamentos e pessoas ao longo da coleta e entrega de produtos acabados e insumos. Consequentemente, os processos de logística devem mudar radicalmente seus padrões de comportamento através da integração de sistemas cyber-físicos. As empresas já começaram a implementar tecnologias da Internet das coisas baseadas em RFID (LEE; LEE, 2015 p. 431-440).

As grandes organizações já estão prevendo as mudanças que a globalização está proporcionando, dentre elas, o avanço tecnológico em todas as áreas, na logística não é diferente. Com o passar dos anos, os pesquisadores vêm se esforçando para o desenvolvimento caminhar para outros tipos de sistemas mais avançados, inteligentes e robotizados (LEE; LEE, 2015).

De acordo com Shankar et al. (2015), a chave para a visualização do material intransit são as nuvens baseadas em GPS e a tecnologia dos identificadores de rádio frequência (RFID) que fornecem identidade, localização e rastreamento. Esses são os pontos principais da logística 4.0 e estão ligadas diretamente a cadeia de suprimentos. Diante da utilização das tecnologias GPS e RFID, os colaboradores envolvidos na cadeia de suprimentos terão acesso às informações de previsão de coleta e entrega de produtos e serviços, como tempo de chegada, monitoramento de movimentação, acesso as condições climáticas da região, assim facilitando o fluxo de entregas das empresas.

\subsection{AUTOMAÇÃo}

A automação industrial tem como objetivo facilitar e agilizar processos realizados por máquinas e pessoas, utilizando a tecnologia para isso. Um dos grandes avanços que a automação pode proporcionar é a autonomia de atividades que ate então era realizadas por um operador ou precisaria de fiscalização contínua.

Automação é um recurso para transformar tarefas repetitivas em processos automáticos, realizados por máquinas. Por meio dela, tarefas suscetíveis a erros humanos como anotação do peso de uma mercadoria, preenchimento de um cheque, por exemplo, quando feitas de maneira informatizada, ganham velocidade e eficiência (SEBRAE, 2019).

Atualmente a automação está sendo utilizada em algumas áreas, auxiliando na produção, na logística e na administração de grandes empresas, o (SEBRAE 2019) destaca algumas aplicações práticas, sendo elas:

1. Alimentação: Venda descentralizada por meio de comandas eletrônica e terminais touch screen, favorecendo a presença mais ativa do garçom junto ao cliente;

2. Varejo: Pré-vendas, por meio de PDAs e terminais touch screen, catálogos eletrônicos, web commerce;

3. Hotelaria: Reservas, check in, check out dos hóspedes; 
4. Supermercados: Geração de informações por meio de balanças inteligentes, exibição eletrônica dos preços diretamente nas gôndolas;

5. Postos de combustível: controle integrado das bombas, serviços, loja de conveniência.

\subsubsection{Robótica}

A robótica industrial teve inicio em na General Motors, no fim da década de 50, quando George Devol e Joe Engleberger projetam o Unimate, que era um braço mecânico automatizado utilizado na linha de produção automotiva (Pinto, 2019). Ela pode ser entendida como uma área que abrange várias outras, como: física, matemática, algumas engenharias, inteligência artificial, podendo se estender a várias outras disciplinas.

Ullrich (1987) define o termo robô como sendo um equipamento multifuncional e reprogramável, projetado para movimentar materiais, peças, ferramentas, para a execução de uma infinidade de tarefas. Neste sentido, é importante salientar que um robô programado de acordo com as necessidades do usuário pode trazer avanços importantes, tanto nas pesquisas acadêmicas quanto nos meios de produção nas pequenas e grandes indústrias.

\subsubsection{Veículos Aéreos Não Tripulados (VANT)}

O termo "Veículo Aéreo Não Tripulado" é reconhecido em todos os meios científicos tecnológico pelo mundo e inclui uma vasta gama de opções de aeronaves, onde podem ser divididas em autônomas, semiautônomas ou remotamente operadas. Segundo a ABA (Associação Brasileira de Aeromodelismo), a definição para Veículo Aéreo Não Tripulado (VANT) é: "um veículo capaz de voar na atmosfera, fora do efeito de solo, que foi projetado ou modificado para não receber um piloto humano e que é operado por controle remoto ou autônomo". O Sistema Aéreo Não Tripulado (SANT) significa o conjunto de veículos aéreos não tripulados, seus controles de voo e seu sistema de operação, isto é, a união de todas as atividades que estão interligadas no plano de voo (RASI, 2008).

Medeiros (2007) destaca que "os veículos Aéreos Não Tripulados (VANT) são pequenas aeronaves, sem qualquer tipo de contato físico direto, capazes de executar diversas tarefas, tais como monitoramento, reconhecimento tático, vigilância e mapeamento entre outras"

De acordo com Neris (2001), os VANT têm como componente principal um sistema de controle capaz de manter a aeronave estabilizada e de executar manobras que a conduza através de uma rota e missão selecionada. Na Figura 1 é possível observar os componentes principais que compõe o veículo aéreo não tripulado. 
Figura 1: Representação dos tipos de VANT e seus componentes

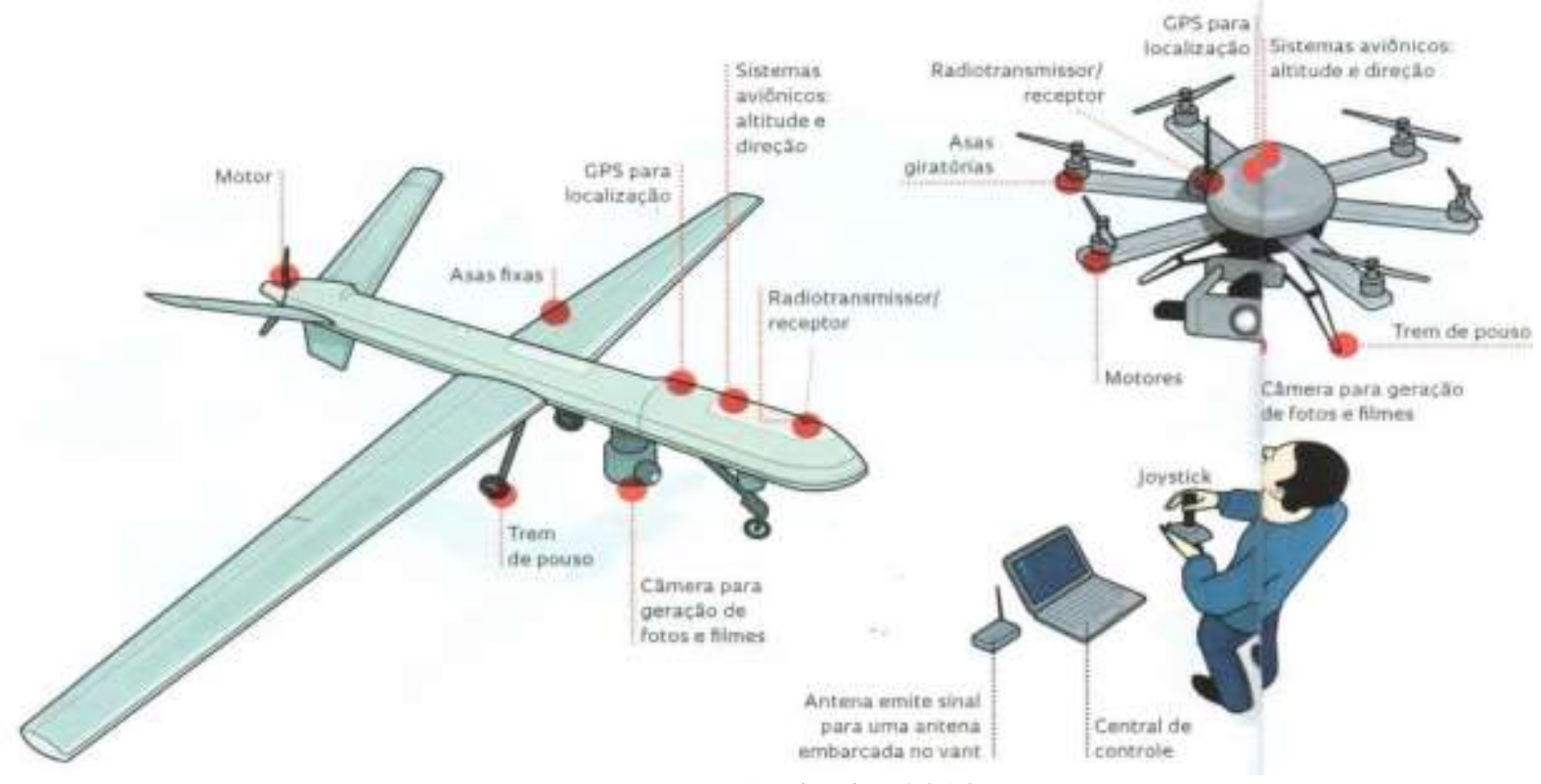

Fonte: Andrade (2013)

O veículo aéreo não tripulado do tipo multi-rotor é uma plataforma aérea com alto nível de sofisticação eletrônica embarcada que possibilita transportar sistemas e capturar imagens para diversas finalidades.

\section{METODOLOGIA}


Figura 2: Esquema de representação do processo de desenvolvimento do produto.

\section{PESQUISA E DESENVOLVIMENTO DE PRODUTO}

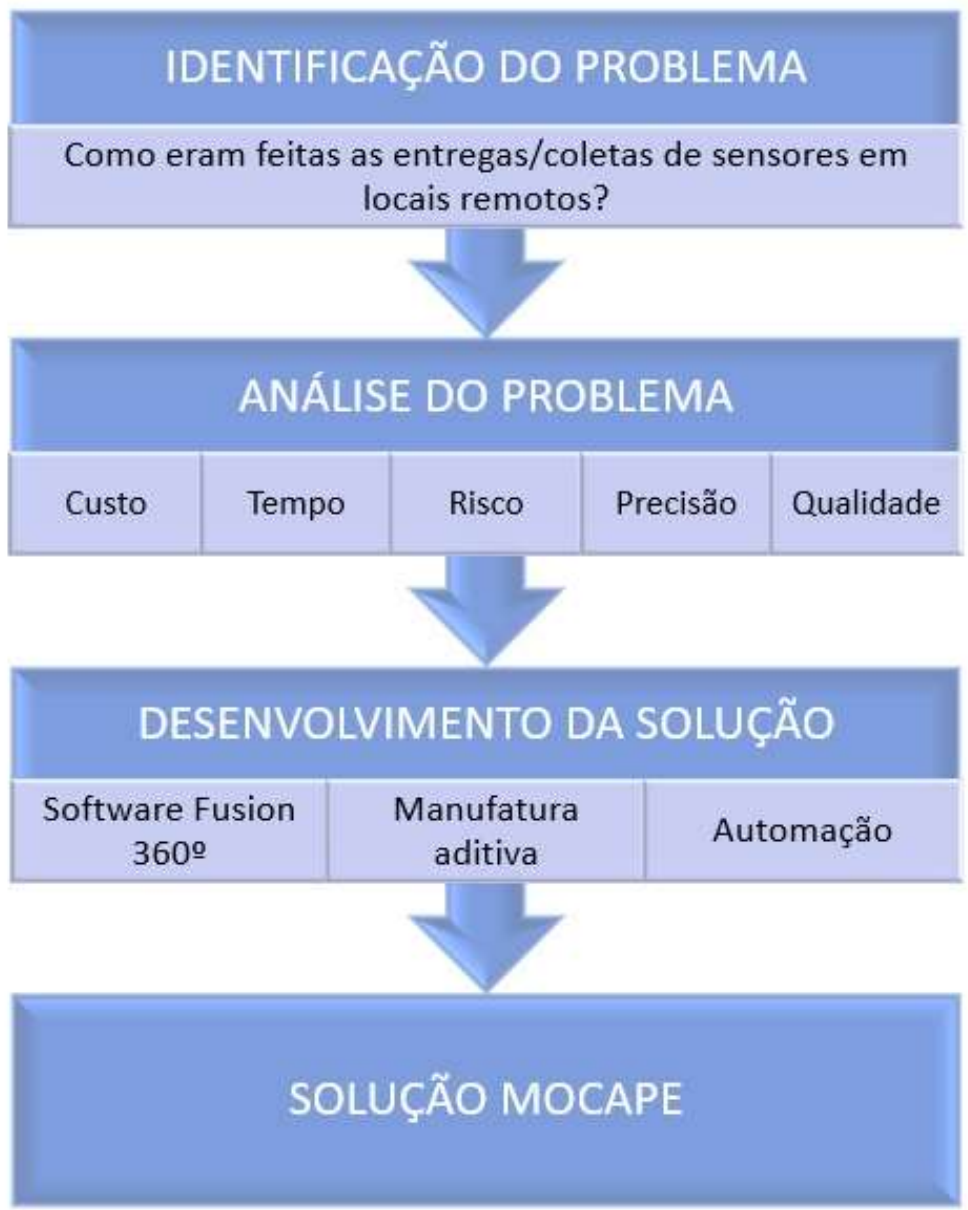

Fonte: Autoria Própria (2019).

\subsection{IDENTIFICAÇÃO DO PROBLEMA}

O desenvolvimento do produto se deu a partir da percepção de limitações no que diz respeito ao transporte de dispositivos eletrônicos e sensores para locais remotos ou de difícil acesso, como matas fechadas, elevações e depressões geológicas bruscas, construções abandonadas ou comprometidas, entre outros, os quais normalmente são realizados por pessoas através de veículos automóveis ou a pé, e, por vezes, o local desejado se quer pode ser acessado, em virtude de barreiras, podendo elas serem naturais ou não.

\subsection{ANÁLISE DO PROBLEMA}

Várias circunstâncias podem ser observadas no que tange o método tradicional da 
logística dos sensores. Um dos pontos facilmente percebidos é a questão do tempo. Tendo em vista que, não dificilmente, por vezes, é necessário obter-se dados variados de localidades remotas, as quais não possuem nenhum sensoriamento, levando pesquisadores ou demais interessados em tais dados a deslocarem os equipamentos necessários por longos trajetos, muitas vezes através de rotas difíceis ou até mesmo não conseguindo ter acesso ao exato local desejado. Tais problemas também tornam esse processo logístico oneroso, mobilizando recursos como automóveis, equipamentos para acesso a locais difíceis e/ou pessoas. Atrelado a isso vem o risco oferecido aos colaboradores e equipamentos envolvidos no processo logístico, o que é convertido em um maior custo. Por fim, a impossibilidade de se acessar determinados locais, problema que frequentemente é observado, muitas vezes afeta negativamente a capacidade dos envolvidos de atingirem seus objetivos, comprometendo os resultados esperados da aplicação de tais equipamentos.

\subsection{DESENVOLVIMENTO}

O desenvolvimento do projeto se deu a partir da necessidade de transportar sensores de diversos tipos e com diversas finalidades para locais de difícil acesso, locais inóspitos no geral, bem como para locais comuns onde há a necessidade de monitoramento remoto.

A priori, uma parte do projeto foi desenvolvida em plataforma de modelagem virtual da AutoDesk (Fusion $360^{\circ}$ ), que possibilitou que houvesse simulações prévias a fim de identificar possíveis interferências, folgas ou até mesmo falta de compatibilidade do produto com a proposta do projeto.

A garra, e todos os suportes, foram projetados em 3 dimensões e após a conclusão foram impressos em impressora 3D com o uso de materiais biodegradáveis (PLA e ABS), que tem seu processo de degradação ativado por enzimas ou por hidrolise e fotodegradação.

A utilização de manufatura aditiva deu-se pelo fato de que possui baixo custo e maior flexibilidade de produção. A expressão "manufatura aditiva" é um termo usado para descrever o processo de manufatura ao qual várias camadas de um determinado material é sobreposta, uma por uma, progressivamente, até formar-se o objeto que originou-se de um modelo digital. Com a utilização da manufatura aditiva e de microcontroladores de alta eficiência, o desenvolvimento do projeto parte para chamada indústria 4.0. Não obstante, a utilização de ferramentas colaborativas de armazenamento em nuvem também possibilita a caracterização da mesma sendo assim corroborada com a IoT (Internet of Things), fornecida pelos microcontroladores.

Após a a modelagem em 3D e impressão, os equipamentos foram montados, configurados e testados. A garra, composta por 4 hastes e controlada por um servo motor que por sua vez é controlado por um microcontrolador, acionado remotamente. Complementarmente, utilizou-se algoritmos para o desenvolvimento de visão computacional e pesquisas necessárias para o desenvolvimento, suporte e finalização do projeto. 


\section{RESULTADOS}

A árvore do produto, contendo todos os componentes do produto desenvolvido, pode ser visualizada através da Figura 3.

Figura 3: Esquema representativo da árvore do produto.

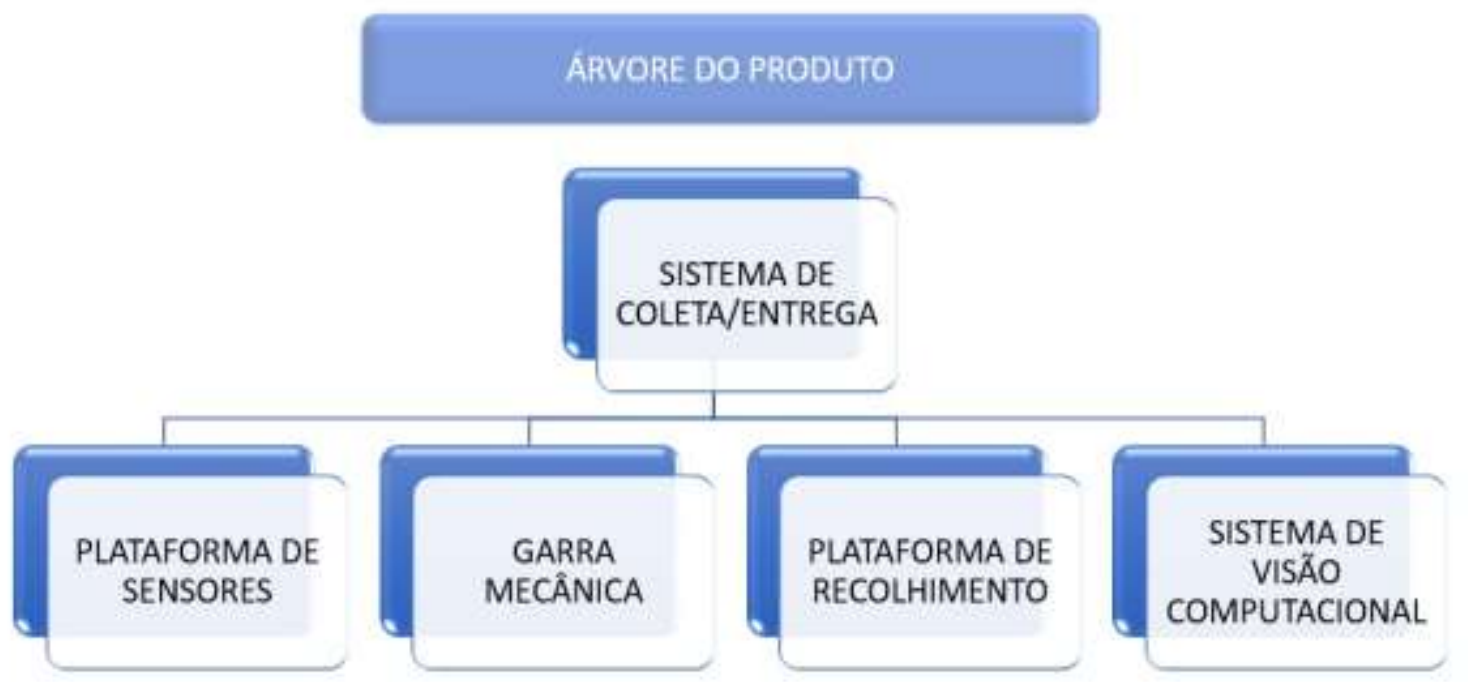

Fonte: Autoria Própria (2019).

A partir da Figura 3, pode-se perceber que o Sistema de Coleta/Entrega de sensores através de VANT (item pai) é composto de 4 itens filho: plataforma de sensores, garra mecânica, plataforma de recolhimento e sistema de visão computacional.

\subsection{Plataforma de SenSOReS}

A plataforma de sensores foi desenvolvida com o intuito de enclausurar os sensores, tanto para proteger de impactos quanto para proteger de umidade e aquecimento natural. A plataforma é composta pelo material PLA (ácido polilático), um material biodegradável. Essa plataforma também emitirá ondas infravermelho para auxiliar o sistema de visão computacional.

A plataforma tem um revestimento em borracha, onde há uma maior aderência junto a garra mecânica. Esse material emborrachado dificulta quedas e maus funcionamentos. A Figura 4 mostra a plataforma de sensores. 


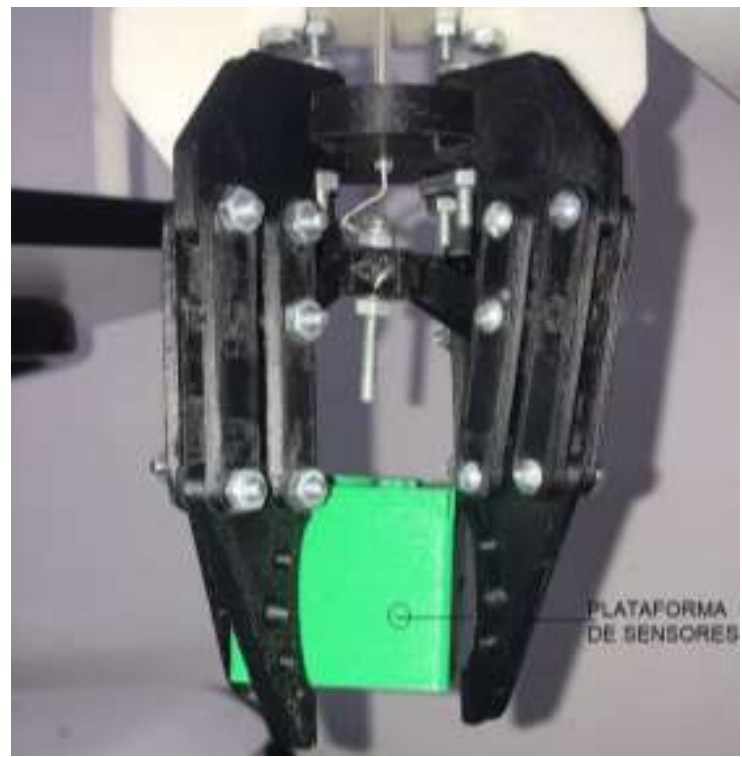

Fonte: Autoria Própria (2019)

\subsection{GARRA MECÂNICA}

A garra mecânica funciona em conjunto com a plataforma de sensores e com o acionamento da plataforma de recolhimento. A garra mecânica também é acionada por um servo motor que é conectado a um eixo, que é parafusado a uma peça central que por sua vez é conectado as 4 pinças da garra de movimentação. A garra mecânica é composta por 30 peças ligados por encaixe e parafusos.

O objetivo principal da garra mecânica é a entrega e a coleta das plataformas de sensores em áreas de pesquisa. A flexibilidade de produção em impressora 3D usando filamentos PLA, um material biodegradável e resistente, aumenta sua viabilidade. O seu funcionamento usando servo motor em consonância com a uma eficiente aderência do material, faz com que a plataforma de sensores fixe nas pinças da garra mecânica. A Figura 5 mostra a garra mecânica acoplada a um VANT.

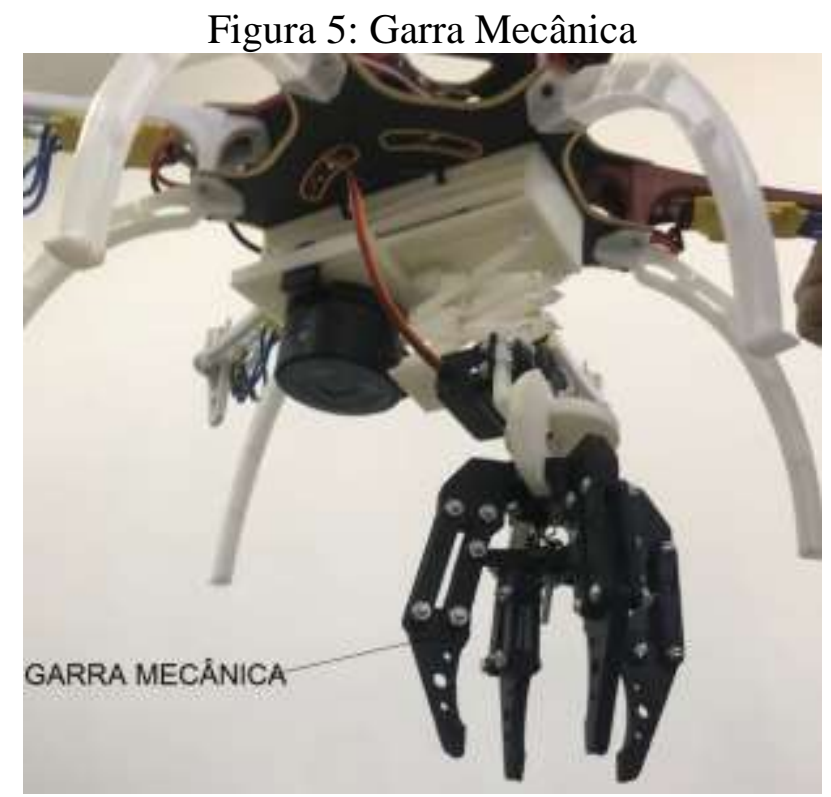

Fonte: Autoria Própria (2019) 


\subsection{Plataforma de Recolhimento}

A plataforma de recolhimento tipo sanfona foi desenvolvida a partir da impressora 3D em material plástico. Ela é conectada ao VANT e à garra mecânica e é acionada por um servo motor. O seu objetivo é levar a garra mecânica até a plataforma de sensores e fazer o seu recolhimento, onde é acionado remotamente. A Figura 6 ilustra o equipamento supracitado.

Figura 6: Plataforma de recolhimento tipo sanfona.

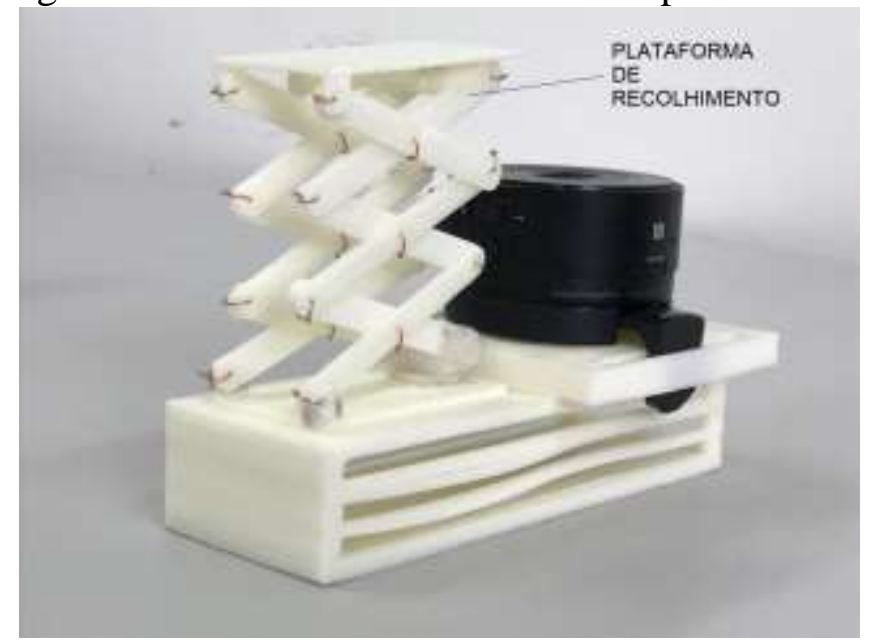

Fonte: Autoria Própria (2019)

\subsection{SISTEMA DE VISÃO COMPUTACIONAL}

O sistema de visão computacional é composto por uma controladora e uma câmera. Esse sistema tem como objetivo fazer a leitura infravermelho da plataforma de sensores. Essa leitura de ondas infravermelho indica a localização exata da plataforma de sensores, evitando perda dos equipamentos e dando mais mobilidade (flexibilidade) ao sistema. A Figura 7 mostra a câmera do sistema de visão computacional junto a plataforma de recolhimento.

Figura 7: Câmera do sistema de visão computacional

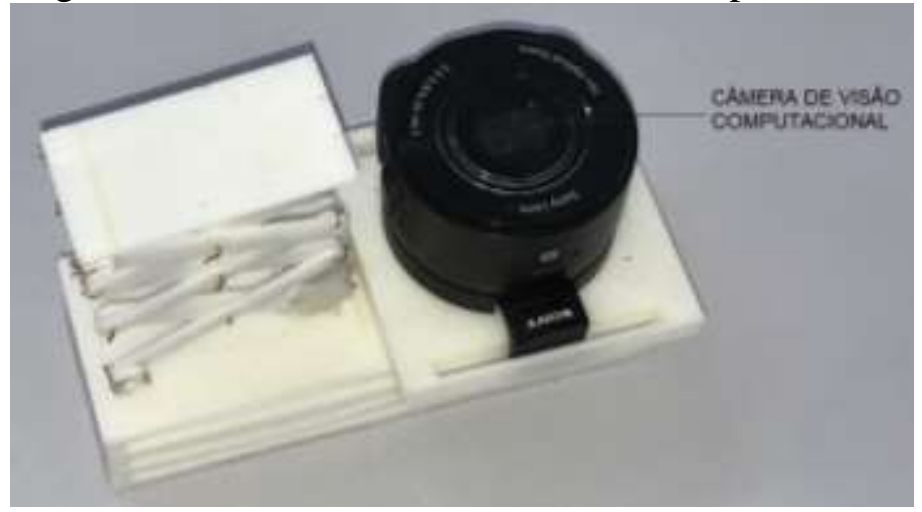

Fonte: Autoria Própria (2019)

\subsection{SISTEMA DE COLETA/ENTREGA}

O VANT, sistema de visão computacional, plataforma de recolhimento tipo 
sanfona, garra mecânica e a plataforma de sensores formam o sistema de coleta e entrega de sensores, objeto de estudo deste artigo. Além da controladora de navegação, o VANT também é equipado com a controladora do sistema de visão computacional e com a controladora da movimentação mecânica da garra e da plataforma e recolhimento.

O sistema de visão computacional também é equipado de uma câmera para fazer a leitura das ondas infravermelho emitidas pela plataforma de sensores. A plataforma de recolhimento tipo sanfona é formado pelo conjunto de peças e um servo motor, responsável pela sua movimentação mecânica. A garra mecânica é formada pelo conjunto de peças, junto com um servo motor que é responsável pela movimentação mecânica da garra. A plataforma de sensores é responsável por fazer a proteção dos sensores de coleta de dados, também responsável por auxiliar na navegação do VANT através do sistema de visão computacional.

A partir do comando remoto do piloto (operador), o sistema de entrega de sensores é acionado para executar às seguintes tarefas:

1. A garra mecânica recolhe a plataforma de sensores;

2. A plataforma de recolhimento tipo sanfona faz o recuo da garra mecânica com a plataforma de sensores;

3. O VANT é acionado e a localização para coleta de dados é definido;

4. O VANT faz o transporte até a localização definida;

5. O operador aciona a plataforma de recolhimento;

6. A garra mecânica faz um movimento de abertura das pinças;

7. A plataforma de sensores é entregue no local.

De maneira análoga ao procedimento de entrega, para o recolhimento da plataforma de sensores o piloto (operador) aciona o sistema recolhimento de sensores para executar às seguintes atividades:

1. O VANT é deslocado até o local em que a plataforma de sensores está;

2. O sistema de visão computacional é acionado, a câmera faz a leitura das ondas infravermelho emitidas pela plataforma de sensores;

3. O operador aciona a plataforma de recolhimento, levando a garra até a plataforma de sensor;

4. A garra mecânica faz a captura da plataforma de sensores;

5. O VANT faz o transporte da plataforma até o operador.

A Figura 8 mostra o sistema de coleta/entrega de sensores em VANT. 
Figura 8: Sistema de coleta/entrega

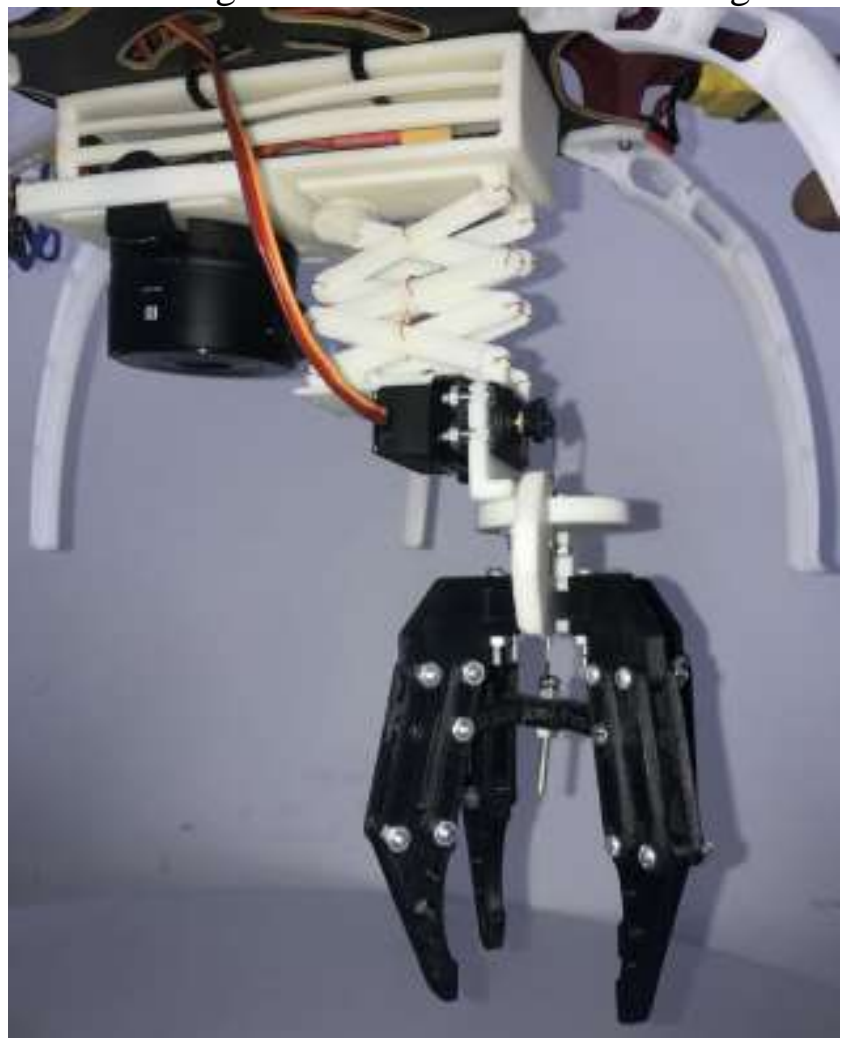

Fonte: Autoria Própria (2019)

A Figura 9 mostra o sistema de coleta/entrega de sensores de um outro ângulo, em que se pode observar o acoplamento de todo o sistema desenvolvido ao VANT.

Figura 9: Sistema acoplado ao VANT

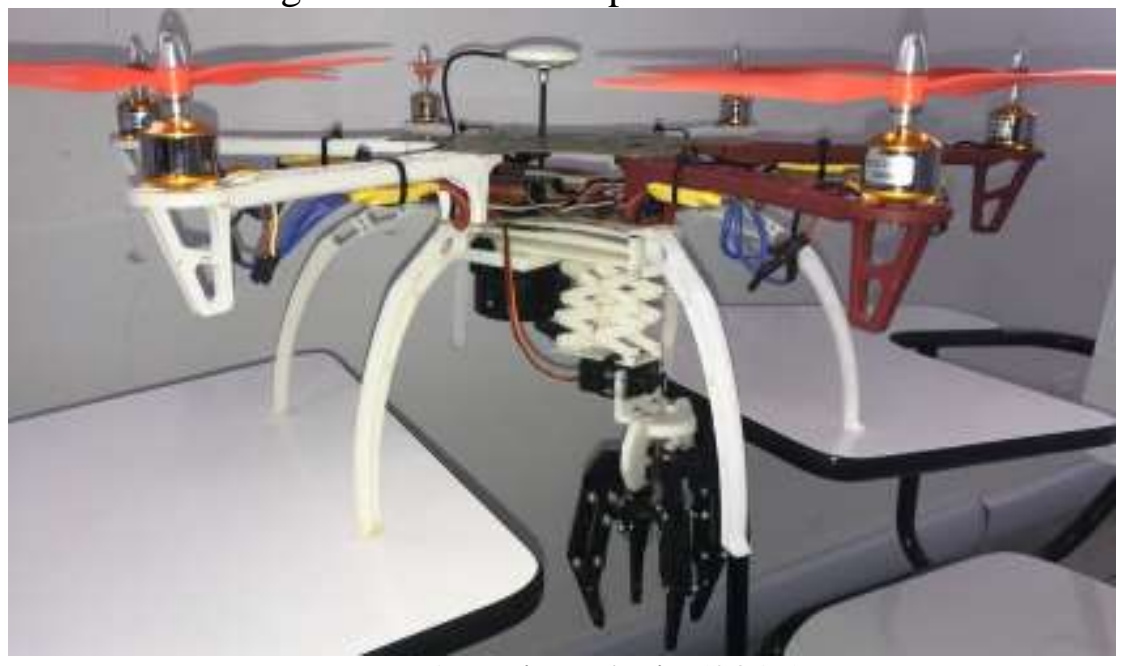

Fonte: Autoria Própria (2019). 


\section{CONSIDERAÇÕES FINAIS}

Este artigo teve como objetivo mostrar o desenvolvimento de um sistema de coleta/entrega de sensores através de Veículos Aéreos Não Tripulados. Para tanto, o produto foi desenvolvido a partir de estudos e pesquisa relacionados a área de automação aplicada nos VANT e logística com o objetivo de transportar sensores de diversos tipos, e com diversas finalidades, para locais de difícil acesso, locais inóspitos no geral, bem como para locais comuns onde há a necessidade de monitoramento remoto. $\mathrm{O}$ resultado gerado neste trabalho indica viabilidade técnica e econômica do projeto, além de possibilitar que pesquisadores, técnicos e pilotos tenham mais flexibilidade, segurança, eficiência e qualidade na coleta de dados a serem coletados a partir dos sensores instalados. Complementarmente, esse projeto é caracterizado pelo avanço e inovação tecnológico nas áreas de Logística e Indústria 4.0.

\section{REFERENCIAS}

[1] ANDRADE, R. O. O voo do Falcão. Pesquisa FAPESP, n. 11, 2013.

[2] BALLOU, R. H. Logística Empresarial: transportes, administração de materiais e distribuição física. 1. ed. São Paulo: Atlas, 2009.

[3] BHARADWAJ, A. et al. Digital businessstrategy: toward a next generation of insights. MIS Quarterly, v. 37, n. 2, p. 471-482, 2013.

[4] CARVAlHO. F., Práticas de planejamento estratégico e sua aplicação em organização do terceiro setor. 2004. p, 207. Dissertação (Mestrado). Universidade de São Paulo faculdade de economia, administração e contabilidade departamento de administração programa de pós-graduação em administração. São Paulo, 2004.

[5] COLOMINA, Ismael; MOLINA, Pere. Unmanned aerial systems for photogrammetry and remote sensing: A review. ISPRS Journal of Photogrammetry and Remote Sensing. v. 92, p. 79-97, 2014.

[6] DOSI, Giovanni et al. Technical change and economic theory. London: Printer Publishers, 1988.

[7] KOTLER, Philip \& KELLER, Kevin Lane (2006). Administração de Marketing. Ed. Pearson Education. 12. ed. São Paulo: Pearson Education.

[8] LONGHITANO, G. A. VANT para sensoriamento remoto: aplicabilidade na avaliação e monitoramento de impactos ambientais causados por acidentes com cargas perigosas, Dissertação (Mestrado em Engenharia de Transportes) Universidade de São Paulo; 163f, 2010.

[9] LEE, I.; LEE, K. The Internet of things (IoT): applications, investments, and challenges for enterprises. Business Horizons, Blomington, v. 58, n. 4, p. 431-440, 2015.1

[10] MEDEIROS, F. A. Desenvolvimento de um veículo aéreo não tripulado para aplicação em agricultura de precisão. 2007. 102 f. Dissertação (Mestrado em Engenharia Agrícola)- Universidade Federal de Santa Maria, Santa Maria, 2007.

[11] NERIS, L. O. Um piloto automático para as aeronaves do projeto ARARA. 2001. 102 f. Dissertação (Mestrado em Ciências da Computação)Universidade de São Paulo, São Carlos.

[12] PINTO, C. A. (Fevereiro de 2019). Um estudo a partir da oficina de robótica educacional no colégio. Rio de Janeiro, Brasil. 
[13] RASI, J. R. Desenvolvimento de um veículo aéreo não tripulado para aplicação em pulverização agrícola. 2008. 70 f. Dissertação (Mestrado em Engenharia Rural)-Universidade Federal de Pelotas, Pelotas.

[14] SEBRAE. (16 de MAIO de 2019). Conheça a importância das ferramentas de automação comercial. Fonte: SEBRAE: http://www.sebrae.com.br/sites/PortalSebrae/ufs/ap/artigos/conheca-a- importanciadas-ferramentas-de-automacao comercial,c058105e03380610VgnVCM1000004c00210aRCRD

[15] SHANKAR, U. et al. How the internet of things impacts supply chain. Inbound logistics. 2015. Disponível em: https://www.inboundlogistics.com/cms/article/how-the-internet-of-things-impactssupply-chains/. Acesso em: 16 mai. 2019.

[16] ULLRICH, R. A. Robótica - Uma introdução. O porquê dos robôs e seu papel no trabalho. Rio de Janeiro: Editora Campus, 1987. 